\title{
EDITORIAL
}

\section{Preparticipation Evaluation of the Wilderness Athlete and Adventurer}

Over the past several decades, wilderness, adventure, endurance, and extreme events have seen a surge in popularity both in the United States and around the world, with increasing number of events and participants each year. These sports may include disciplines such as hiking, trail running or biking, various ultraendurance and adventure races, mountaineering, rock climbing, caving, diving, surfing, and white-water paddling. Events often occur at environmental extremes involving hot and cold climates, variable weather, water conditions, and high altitude. Events are becoming increasingly more challenging and involve remote locations that increase the potential for injury, illness, and worsening of existing medical conditions. In addition to foot travel and bicycles, modalities by which people are accessing the more remote backcountry involve ground vehicles such as motor-cycles/all-terrain vehicles, snow machines, airplanes, helicopters, and large watercrafts. The extent to which expeditions and adventures are taking place is deep and often very remote, thus increasing the level of inherent risk. This genre of sport appeals to a broad spectrum of individuals, many of whom are middle-aged or older, may include families with young children, and other special populations of individuals. Wilderness sports and adventures combine the traditional risks of physical activity and exertion with the remoteness and exposure associated with backcountry environments.

The purpose of this Wilderness Medical SocietyAmerican Medical Society for Sports Medicine (WMSAMSSM) collaboration is to outline an appropriate process for evaluation of wilderness athletes and adventurers, to factor comorbidities and unique event and environment demands into the preparticipation evaluation (PPE), and to advise on education, prevention, and training specific to these unique individuals.

The need for this collaboration became apparent at the Wilderness Medical Society Summer Annual Meeting in 2013 in Breckenridge, Colorado, where Wilderness

The authors report no conflicts of interest.

This article appears in a "Care of the Wilderness and Adventure Athlete" special issue, jointly published by Clinical Journal of Sport Medicine and Wilderness \& Environmental Medicine.
Medical Society members Arthur Islas and Aaron Campbell and American Medical Society members Chris Madden and Chad Asplund presented and participated in a 2-day preconference workshop on the wilderness athlete and later gathered for a main conference roundtable discussion addressing PPE considerations about the wilderness athlete and adventurer. The workshop was well attended and received as was the main conference, which continued on with the Wilderness Athlete theme. Various issues came up and were discussed, and it was noted there was little literature to guide medical evaluation of individuals participating in wilderness sports and adventures. Unique issues such as extrication, medical conditions at altitude and in extreme environments, individualized event planning, and other topics specific to wilderness that are different than traditional sports, were brought to the table.

A discussion focused on evaluation rather than "clearance" for sport in the typical PPE fashion, and important issues such as risk assessment and tolerance consultation as well as shared decision making were reviewed. Participants also entertained how to best approach wilderness athletes and adventurers with current tools and individualized considerations such as (1) the traditional PPE monograph, ${ }^{1}$ (2) other published preparticipation and screening recommendations, many not directly applicable or appropriate here (Maron cardiovascular screening $>50$ years, ${ }^{2}$ American College of Sports Medicine exercise testing guidelines ${ }^{3}$ ), (3) unique needs of individual athletes and adventurers and comorbidities that may worsen in wilderness situations and/or may lead to problems adjusting to or coping with specific event and adventure demands (eg, pulmonary hypertension and altitude), and (4) unique adventure and event considerations for individuals and others in groups on trips or expeditions who may be affected. All conference presenters agreed on the need for a go to PPE resource for physicians and other health professionals evaluating athletes and adventures in these unique and challenging environments.

The PPE has been a traditional part of organized sports for many years. It is formally endorsed by 6 national societies, and likely referenced by more. The 
initial publication of the PPE Monograph in 1992 set the initial standard for the process with the main goal to promote the health and safety of athletes while training and not to exclude them from competition. Although the PPE Monograph has been updated several times, the primary goals remain the same: to detect potentially lifethreatening or disabling medical or musculoskeletal conditions and to screen for conditions that may predispose an athlete to injury or illness. Secondary goals include determining general health, to serve as an entry point to health care to those who otherwise would not seek physician care, and to provide an opportunity to initiate discussion on health-related topics.

Most of the knowledge conferred by the fourth edition of the PPE Monograph (PPE 4) deals with conventional sports played in stadiums, on courts, and on fields with traditional medical care readily available. However, to date, there has been no document that details the potential risks unique to wilderness and adventure sports (or those that occur in extreme or austere environments), comorbidity considerations specific to these environments, or the clearance process for the athletes and adventurers to participate in these events. The PPE process demands a unique individualized approach when evaluating wilderness athletes and adventurers.

The traditional PPE was created, designed, and intended for high school and collegiate-level athletes. ${ }^{4}$ However, wilderness athletes include individuals from both sexes and of varied ages (typically older than school-aged athletes). ${ }^{5}$ Second, the PPE was designed for athletes in organized sports under supervision and with access to emergency services. ${ }^{2}$ Most wilderness activities are not supervised, and the athlete is solitary or with a small group. Self rescue whenever possible is imperative, and access to emergency and rescue services is limited. When rescue services are called upon, the time needed for arrival on location, scene safety and patient assessment, and transport to definitive care is exponentially longer. Therefore, greater emphasis must be made on prevention of injury. The practitioner conducting the PPE must vary from the standard examination and address the common causes of wilderness athlete morbidity and mortality in an effort to educate the athlete and prevent as many incidents as possible. Finally, the PPE is designed to be done quickly and in large sessions. For wilderness athletes, this approach is inappropriate because extensive education and additional screening may be needed. In addition, unlike organized or team sports that usually have a defined season with a definite beginning and end and screening can be done in the preseason, wilderness sports are participated in year round, individuals can continually be active in wilderness sports uninterrupted for many years, and each event or adventure may present unique risks and demands. Few focused disease-specific PPE forms exist for wilderness activities, ${ }^{1,6}$ and participants frequently bring in vendor or guide-specific paperwork to be "cleared" for expeditions or events. A onetime-only general PPE screening of athletes is not sufficient. Guided concessions on Mount McKinley in Denali National Park are requiring a physician evaluation to have been completed within 1 year of participation on a guided expedition. The Denali National Park Service requires a 60-day in advance application process before any individual embarking on a permit required expedition, which could include mountaineering or glacier traversing in the park boundaries. The purpose of such requirements is to promote individual safety and to reduce risk. In the case of guided expeditions, all the guided concessions on Mount McKinley require a physician medical clearance. The fundamental concern is that no careful standardized guidelines for such clearance are published, and few recommendations are available, none of which are easily accessible.

Consequently, different strategies are needed for the wilderness PPE, which include education about the causes of morbidity and mortality in wilderness athletes, counseling on the prevention and treatment of event and environment-specific injuries and illnesses, and screening of athletes at risk for illness or injury. Proper screening and evaluation for participation should mitigate some of the risk of injuries, illnesses, and deaths in wilderness and adventure athletes and should allow for safer participation for recreational wilderness adventurers.

Chad A. Asplund, MD, MPH, FACSM Student Health Services and Sports Medicine, Georgia Regents University Augusta, Georgia E-mail address: chad.asplund@gmail.com

Chris Madden, MD

American Medical Society for Sports Medicine, Longs Peak Family Practice, Longmont, Colorado

Aaron Campbell, MD, MHS

Family Medicine, University of Utah School of Medicine, Salt Lake City, Utah

Arthur A. Islas, MD, MPH

Wilderness Medical Society and Sports Medicine, Department of Family and Community Medicine, Texas Tech University, El Paso, Texas 


\section{References}

1. American Academy of Family Physicians, American Academy of Pediatrics, American College of Sports Medicine, American Medical Society for Sports Medicine, American Orthopaedic Society for Sports Medicine, American Osteopathic Academy of Sports Medicine, PPE Preparticipation Physical Evaluation. 4th ed. Minneapolis, MN: McGrawHill; 2010.

2. Maron BJ, Douglas PS, Graham RA, et al. Task force 1: preparticipation and diagnosis of cardiovascular disease in athletes. J Am Coll Cardiol. 2005;45:131322-131326.
3. Thompson WR, Gordon NF, Pescatello LS. American College of Sports Medicine Guidelines for Exercise Testing and Prescription Philadelphia, PA: Lippincott Williams \& Wilkins; 2010.

4. Giese E, O'Connor F, Depenbrock P, et al. The athletic preparticipation evaluation: cardiovascular assessment. Am Fam Physician. 2007;75:1008-1014.

5. Montalvo R, Wingard DL, Bracker M, et al. Morbidity and mortality in the wilderness. West J Med. 1998;168:248-254.

6. Doan D, Luks AM. Wilderness and adventure travel with underlying asthma. Wilderness Environ Med. 2014;25: $231-240$

Corresponding author: Chad A. Asplund, MD, MPH, FACSM, Student Health Services and Sports Medicine, Family Medicine, Georgia Regents University and Augusta Greenjackets, Paine College, Augusta, GA 30912 